\title{
Novo retorno a Saussure: algumas reflexões sobre a circulação indefinida do nome de Ferdinand de Saussure
}

Assistimos atualmente a mais um retorno a Saussure, motivado, sem dúvida, pelas comemorações do centenário de morte do autor em 2013 e do centenário de publicação do Curso de Linguística Geral (CLG) em 2016. São inúmeros encontros científicos no cenário nacional e internacional, teses, livros, artigos ${ }^{1} \ldots$ que atestam a presença viva das ideias de Saussure no debate contemporâneo em torno da linguagem. Além disso, tem-se hoje uma noção mais exata do caráter extremamente plural das preocupações de Saussure, que não se reduzem, de modo algum, à linguística geral, estendendo-se a domínios muito diversos, como a semiologia, epistemologia da gramática comparada, filosofia da linguagem, mitografia, crítica literária, filosofia hindu, glossolalia... Enfim, além das preocupações de ordem histórico-filológica, procura-se também, nesse novo retorno, reavaliar a atualidade do pensamento de Saussure, sua produtividade no cenário contemporâneo.

Mas, apesar do reconhecimento atual do caráter plural e produtivo das ideias de Saussure, a imagem do linguista que se continua a veicular nos cursos e manuais de introdução à linguística é a velha imagem daquele Saussure estruturalista, que, por um lado, funda a linguística moderna, pelo que é aclamado, e, por outro, censura o desenvolvimento de pesquisas para além do estudo da língua considerada em si mesma e por si mesma, pelo que é, ao contrário, criticado. Trata-se da já tão repisada representação segundo a qual Saussure é o fundador da linguística moderna, mas um fundador que, ao delimitar o objeto

\footnotetext{
1 Apenas para fornecer uma rápida ideia da presença de Saussure no cenário contemporâneo, poderíamos fazer menção aqui a encontros como, por exemplo, o Congresso Internacional 100 anos com Saussure promovido pela Universidade de São Paulo em setembro de 2013, ou, nesse mesmo período, a Jornada Internacional Ferdinand de Saussure e os Estudos Linguísticos Contemporâneos e também o II Simpósio Nacional de Estudos sobre os manuscritos de Ferdinand de Saussure, ambos promovidos pela Universidade Federal do Rio Grande do Norte; as II e III Jornadas de Estudos Saussurianos em outubro de 2013 e setembro de 2016, respectivamente, promovidas pelo IEL/Unicamp; e ainda o Colloque International Le Cours de Linguistique Générale: le Devenir ocorrido em junho de 2016 em Paris e, em janeiro de 2017 em Genebra, o Colloque International Le Cours de Linguistique Générale: l'Émergence. Poderíamos também mencionar a criação do GT Estudos Saussurianos da Anpoll, em 2013, e publicações no cenário nacional, como o livro organizado por Fiorin, Flores e Barbisan intitulado Saussure: a invenção da linguística, publicado em 2013, o livro organizado por Faraco, intitulado O efeito Saussure: cem anos do Curso de Linguística Geral, publicado em 2016 ou ainda o livro organizado por Cruz, Piovezani e Testenoire, intitulado Saussure, o texto e o discurso, publicado nesse mesmo período, livro este que conhece uma versão francesa, publicada na França nesse mesmo ano, além da publicação de números temáticos consagrados ao tema como o fez recentemente a revista Delta. Em 2012, John E. Joseph publica Saussure, um livro que, como observam Alessandro Chidichimo e Valentina Bisconti (2016), já tem seu lugar no panteão dos estudos saussurianos, ao lado de obras como as Sources manuscrites de Robert Godel, ou a edição do CLG de Rudolf Engler (1968/1974) e a de Tullio de Mauro (1967).
} 
da ciência que funda, deixa de fora aspectos fundamentais da comunicação humana, hoje abordados de forma privilegiada pelas disciplinas contemporâneas. Saussure, desse modo, não passaria aos olhos dos linguistas da atualidade, de um autor superado, devendo, todavia, figurar nos currículos de Letras por estar na origem da ciência linguística.

Mesmo que nos restrinjamos ao domínio da linguística geral, essa imagem de Saussure desfaz-se sob nossos olhos, à luz dos novos estudos saussurianos, e as ideias do autor são atualmente objeto de uma revalorização. Com efeito, como mostra uma interessante pesquisa desenvolvida por Pierre-Yves Testenoire (2016), Saussure começa a ser visto hoje - e isso pelos mesmos linguistas que o viam, há algumas décadas, como o pai do estruturalismo - como um autor cujo pensamento se aproxima, mais do que se afasta, da linguística que se pratica atualmente. Assim, Jean-Paul Bronckart, por exemplo, em 1977, considerava Benveniste o precursor das teorias do discurso e, segundo ele, seus trabalhos, se comparados aos de Saussure, "dão prova de uma inegável originalidade" (BRONCKART, 1977, p. 306). De fato, para o Bronckart desse período, os trabalhos de Benveniste “evidenciaram a existência de 'um outro nível de análise linguística', aquele do funcionamento discursivo do sujeito, e demonstraram que esse funcionamento não pode ser descrito nos clássicos termos da análise semiológica” (BRONCKART, 1977, p. 306). Em 2010, porém, Bronckart afirma, sobre Saussure, algo que vai numa direção totalmente oposta: "conforme se pode atestar em múltiplas passagens de sua obra, Saussure defendeu claramente que a dimensão da atividade do discurso sempre precede a língua" (BOTA; BRONCKART, 2010, p. 341). Há, desse modo, em Bronckart, uma importante mudança de posição no tocante à linguística saussuriana.

Num primeiro momento parece que essa mudança de posição só foi possível graças à descoberta em 1996 de novos manuscritos de Saussure, em particular, o manuscrito que se intitulou "Da essência dupla da linguagem", publicado em 2002 nos Escritos de Linguística Geral, ou ainda a redescoberta da "Nota sobre o discurso", que, apesar de já ter sido publicada por Jean Starobinski em 1971, em seu livro intitulado As palavras sob as palavras, era pouco conhecida e foi republicada nos Escritos de Linguistica Geral. Emerge, é verdade, nos anos subsequentes a esse período a ideia de que somente no início do século XXI, com a publicação dos Escritos, é que, enfim, tem-se acesso ao "verdadeiro" pensamento de Saussure sobre a linguística geral. Simon Bouquet afirma, por exemplo, em 2003: "é somente no século XXI que eles [os textos originais da meditação saussuriana sobre a linguagem e sua ciência] se tornam acessíveis, ao mesmo tempo legíveis em sua 
continuidade e servidos da filologia necessária” (2003, p. 12). É evidente que Bouquet não desconhece os trabalhos de Robert Godel (1957), Rudolf Engler (1968/1974) e Tullio de Mauro (1967), mas, para ele, esses trabalhos filológicos estavam presos ao "molde conceitual” do Curso, o que representava, em sua opinião, um obstáculo ao acesso ao "verdadeiro" pensamento de Saussure.

Essa posição de Bouquet não é de modo algum consensual. Jürgen Trabant (2005), Claudine Normand (2004), Christian Puech (neste volume), entre outros, se posicionam contra esse ponto de vista que pretende fazer da relação entre Curso e manuscritos uma relação de oposição radical. Esses autores procuram mostrar que a questão é um pouco mais complicada e não deveria ser reduzida à alternativa cômoda entre um falso e um verdadeiro Saussure. Normand, por exemplo, é cética em relação à possibilidade de um acesso ao "verdadeiro" pensamento de Saussure sobre a linguística geral. Para ela, o pensamento "autêntico" de Saussure chega até nós "por meio de um texto ideal e, como tal, inacessível, de que nós não conheceremos mais do que fragmentos ou uma versão necessariamente reconstituída" (2004, p. 15). Trabant chama a atenção para o fato de que o acesso ao pensamento de Saussure não é pura e simplesmente uma questão de fontes: os Escritos de Linguística Geral, observa o autor, possuem um caráter parasitário em relação ao Curso, isto porque não se pode encontrar nos Escritos um autor compreensível ou coerente, "mas somente fragmentos muito difíceis de serem compreendidos, que ganham certa coerência e certo sentido apenas se os colocamos em relação com o Curso" (2005, p. 124)². É interessante notar que Tullio de Mauro em 1967, com a publicação de sua edição comentada do Curso de Linguística Geral, traduzida para o francês por Louis-Jean Calvet cinco anos mais tarde, já mostrava esse "outro" Saussure (cf. o artigo de Trabant neste volume). Por que, então, uma interpretação estruturalista de Saussure continuou a circular deliberadamente e continua, de certa forma, até hoje?

Calvet, no posfácio que escreve para a tradução francesa da edição de Tullio de Mauro, denuncia a maneira como funcionou o desenvolvimento da linguística, “cristalizando inicialmente um pensamento numa 'vulgata' duvidosa e depois excluindo os

\footnotetext{
${ }^{2}$ Para maiores aprofundamentos, cf. Cruz, 2016. Nesse texto, o autor trata da validade de se ler o CLG depois de um século de sua publicação, fornecendo, ao leitor, na primeira parte do texto, uma resenha sobre a opinião de estudiosos que defendem o descarte do texto de 1916 e estudiosos que, ao contrário, entendem que o conteúdo do CLG não se opõe radicalmente aos manuscritos saussurianos sobre a linguística geral.
} 
manuscritos considerados como inaceitáveis porque não convinham à imagem do pai fundador” (1972, p. 512-513). Em relação às tantas leituras do próprio CLG, Calvet chama a atenção para seu caráter seletivo: "são sempre as mesmas passagens que são citadas, relativas às dicotomias célebres, o signo linguístico e o valor: as terceira, quarta e quinta partes do Curso merecem desse ponto de vista uma releitura à luz das vias hoje exploradas" (1972, p. 512). Diríamos, contudo, que mesmo as partes iniciais merecem um tratamento mais sofisticado.

Com efeito, do nosso ponto de vista, a tentativa de Bally e Sechehaye de fornecer ao público sob a forma de obra acabada um pensamento que se encontrava ainda em pleno processo de formação conduziu à redação de um texto que, finalmente, apesar dessa tentativa louvável de fornecer um apanhado das ideias de Saussure sobre a linguística geral, incorre em contradições não sem importância. São contradições que concernem a temas fundamentais, como a própria delimitação do objeto da Linguística. Assim, por exemplo, ao mesmo tempo em que o CLG apresenta um Saussure que teria concebido a língua como um objeto a ser estudado em si mesmo e por si mesmo ${ }^{3}$, ele também apresenta, por outro lado, um Saussure para quem, ao contrário, nenhuma conclusão é possível quando se estuda a língua fora de sua realidade social e histórica ${ }^{4}$. Não seria esse fato uma das causas fundamentais que fazem com que o pensamento de Saussure tenha vida longa, inicialmente suscitando tentativas de fixação desse pensamento, com fins legitimadores, depois, suscitando a necessidade de um retorno com base em novos manuscritos descobertos mais tarde, com vistas a esclarecer pontos obscuros do texto de 1916 ?

Em relação aos retornos ao nome de Saussure oriundos das tentativas de fixação de seu pensamento com fins legitimadores, é preciso compreendê-los em perspectiva histórica: o CLG procura fornecer uma resposta a um problema de base, que ameaça, no final do século XIX e início do século XX, a própria continuidade da jovem ciência

\footnotetext{
${ }^{3}$ Aqui faz-se referência, como se sabe, à frase que encerra o CLG: "a linguística tem como único e verdadeiro objeto a língua considerada nela mesma e por si mesma” (CLG, p. 317). No quinto capítulo da introdução dessa mesma obra, lemos: "nossa definição da língua supõe que eliminemos tudo o que é estranho a seu organismo, a seu sistema, em uma palavra tudo o que se designa pelo termo de "linguística externa"' (CLG, p. 40).

${ }^{4}$ Depois de afirmar que a língua é a linguagem menos a fala, Saussure observa que "essa definição deixa ainda de fora a realidade social" e que "é preciso uma massa falante para que haja uma língua. Em nenhum momento e contrariamente à aparência, esta existe fora do fato social, porque ela é um fenômeno semiológico. Sua natureza social é um de seus caracteres internos” (CLG, p. 112). Mas Saussure não para por aí: "mas nessas condições, a língua é viável, não viva; considera-se apenas a realidade social, não o fato histórico" (ibid., p. 112). Ele conclui, então, que "fora da duração, a realidade linguística não é completa e nenhuma conclusão é possível” (ibid., p. 113).
} 
linguística que, nesse período, apesar de já gozar de certa estabilidade institucional, vive uma crise de fundamentos sem precedentes. Como afirma Sylvain Auroux, a Linguística nesse momento "é simplesmente incapaz de definir aquilo que é uma língua, de dizer em que consiste exatamente seu objeto" (2000, p. 411). Trata-se aí de um problema cuja resposta suscita toda uma série de implicações fundamentais, o que faz da jovem ciência, que nos anos 1850 parecia enfim bem estabelecida, uma ciência ainda em busca de sua fundação. O Curso de Linguística Geral propõe uma resposta a esse problema, que será acolhida não pelos contemporâneos de Saussure, ainda fortemente imbuídos do espírito do comparatismo, mas, sobretudo, pelos linguistas do leste europeu, que, no final dos anos 1920, consideravam o CLG como portador da novidade em Linguística ao privilegiar o estudo sincrônico. Lemos no item b da primeira tese do Círculo linguístico de Praga, por exemplo, que "a melhor maneira de conhecer a essência e o caráter de uma língua é a análise sincrônica dos fatos atuais”. Esses linguistas, apesar desse reconhecimento, iniciam um modo de leitura do CLG que será dominante entre os linguistas do século XX até os anos 1960/1970 e que consiste na fixação de interpretações, em que se procura silenciar passagens do CLG que representavam um obstáculo à leitura estruturalista desse texto. Tudo isso para justificar a emergência de uma série de projetos. Assim, considerava-se o CLG como o texto fundador da Linguística, mas, ao mesmo tempo, um texto que deveria ser revisto, reformulado e mesmo reescrito (CHISS; PUECH, 1997, 1999; PUECH, neste volume).

No tocante ao retorno ao nome de Saussure com base em novos manuscritos, num primeiro momento, este é caracterizado pela tentativa de suspensão de interpretações, que, então, dá lugar a um trabalho de aprofundamento da leitura de Saussure, desta vez, procurando enfrentar as contradições, compreendê-las, partindo do CLG, certamente, mas confrontando-o com os manuscritos. Esse trabalho iniciado por Godel e continuado por Engler e De Mauro mostrou, finalmente, que o pensamento de Saussure vai muito além de sua interpretação estruturalista, chegando mesmo a desconstruí-la. Num momento posterior, sobretudo a partir da publicação dos Escritos de Linguística Geral, esse trabalho filológico é acompanhado de um viés presentista. Simon Bouquet, por exemplo, que encabeça esse novo retorno filológico a Saussure, pretende, mais do que compreender Saussure, voltar a fixar interpretações, colocando-se no lugar de linguista e procurando, com base nessas interpretações, lançar luzes a problemas contemporâneos. Assim, por exemplo, em "Ontologie et épistémologie de la linguistique dans les textes originaux" [Ontologia e epistemologia da linguística nos textos originais], Bouquet afirma: "minha 
perspectiva [...] será exclusivamente aquela de um linguista. Ela se pretende, além disso, estritamente presentista” (2008, p. 1). Ele precisa então o que ele está entendendo por "perspectiva presentista":

Eu considerarei o pensamento saussuriano apenas do ponto de vista segundo o qual este pensamento pode ser útil, hic et nunc, à disciplina dita linguística. Dito de outro modo: do ponto de vista segundo o qual, podendo ser lido através de um filtro conceitual contemporâneo, ele entra em consonância com problemas atuais das ciências da linguagem e segundo o qual ele constitui, hoje, um programa epistemológico ao mesmo tempo original e ainda amplamente desconhecido (BOUQUET, 2008, p. 1)

O novo retorno a Saussure a que se procede hoje é marcado por propósitos diversos. Como afirmam Cruz, Piovezani e Testenoire, “o desafio que ora se impõe é o de partir dos escritos que Saussure deixou inacabados para completar, deslocar, confirmar ou contestar as teses classicamente recebidas pela leitura do Curso de Linguística Geral' (2016, p. 7). São propósitos, portanto, de ordem filológica, de ordem histórica, mas também de ordem epistemológica.

Este número temático da revista Leitura, que reúne uma pluralidade de autores de diferentes instituições, nacionais e internacionais, atesta muito bem o caráter plural desse novo retorno a Saussure, bem como sua vitalidade e abrangência mundial. Apesar desse caráter plural, as perspectivas assumidas nos trabalhos aqui reunidos têm em comum o fato de fornecerem imagens de Saussure consideravelmente distintas daquelas veiculadas nos cursos e manuais de introdução e de reconhecerem que suas ideias ainda desempenham um importante papel na discussão de problemas contemporâneos da pesquisa linguística. São dezoito artigos de vinte e cinco pesquisadores brasileiros de nove instituições distintas, três traduções de trabalhos de renomados pesquisadores estrangeiros, uma resenha e uma entrevista com o presidente do Cercle Ferdinand de Saussure, Daniele Gambarara.

A problemática da diversidade das línguas e o conceito de língua em Saussure são tratados em dois artigos. Em Da importância da diversidade linguística na conformação do conceito saussuriano de língua, Janaína Nazzari Gomes parte das reflexões de Ferdinand de Saussure acerca do fenômeno da diversidade linguística, com vistas a compreender como tais reflexões contribuíram para a conformação do construto teórico saussuriano sobre a língua. A linguística saussuriana e a multiplicidade das línguas de Fernando Silva e Silva, discute as concepções saussurianas de língua e linguagem, atravessadas por conceitos como os de analogia e virtual, partindo de uma perspectiva histórica e filosófica. 
Manuscritos saussurianos mobilizam questões diversas. Hozanete Lima e Felipe Morais de Melo em Os "fatos de sinonímia" nos manuscritos de F. de Saussure buscam abordar a questão interrogando-se sobre as razões que teriam levado o autor a se interessar pelos "fatos de sinonímia", assim como sobre a maneira pela qual maneja este tipo de manifestação linguística. Em $O$ "som" como figura vocal e o "som” como signo: considerações a partir de De la double essence du langage, Aline Vargas Stawinski discute a que se refere esta dupla essência reiterada pelo linguista. Armadilhas da linguagem: criatividade epistemológica de Ferdinand de Saussure em um manuscrito de 1894, de Vítor Jochims Schneider, aborda a criatividade epistemológica do genebrino a partir da leitura analítica de fragmentos do manuscrito Notes sur l'accentuation lituanienne.

O Curso de Linguistica Geral, herança histórica fundamental do legado saussuriano para a linguística moderna, é especificamente retomado em três trabalhos. Aline Moretto Costa e Luiza Milano em A noção de Gramática em Saussure defendem que os princípios da arbitrariedade, do valor e do mecanismo linguístico fundam um conceito de gramática. $O$ lugar da escrita na reflexão saussuriana sobre o objeto da Linguística, de Giovane Fernandes Oliveira, explora as noções de escrita assim como o seu lugar na delimitação do objeto da ciência da língua. Stefania Montes Henriques investiga as considerações de Ferdinand de Saussure sobre a categoria linguística dos nomes próprios no CLG no artigo $A$ negação da nomenclatura e o isolamento do nome próprio.

Valdir do Nascimento Flores em Comentários sobre as traduções da "Nota sobre o discurso" de Ferdinand de Saussure no Brasil: elementos para leitura da "Nota" se detém sobre as duas traduções brasileiras desse manuscrito saussuriano, mobilizando a noção de retradução para fundamentar a ideia de que as traduções de Saussure no Brasil condensam as leituras que o autor recebeu no contexto brasileiro.

A complexidade das fontes saussurianas atualmente disponíveis e os desafios postos para o pesquisador é também tema de discussão. A problemática acerca da edição das notas saussurianas: um livro sem fim nem começo ou um livro de areia à la Borges? de Amanda Eloina Scherer e Maria Iraci Sousa Costa sustenta que as publicações de notas manuscritas saussurianas apresentam uma ordem que lhes é própria, atribuindo ao texto uma linearidade singular. Micaela Pafume Coelho em Caminhos e retornos: estratégias de abordagem de documentos saussurianos se propõe a analisar e explicitar alguns aspectos do tratamento dos 
documentos saussurianos assim como da própria teorização neles apresentada, destacando seu processo de elaboração e não o produto final.

Eliane Silveira, Israel de Sá e Cleudemar Alves Fernandes em Problemas da autoria em Ferdinand de Saussure: do percurso intelectual à constituição da obra reconhecem o lugar singular assumido pelo linguista em torno da autoria e abordam a questão pela via da descrição e avaliação de seu percurso acadêmico/intelectual tortuoso e da singularidade de sua obra, questionando-se sobre o modo pelo qual o fundador da Linguística Moderna se constitui autor.

As relações de Saussure com outros linguistas, contemporâneos seus ou a ele posteriores, é tema de três artigos. Saussure, Bréal e a questão do sentido de Dayanne Teixeira Lima problematiza o "silêncio" saussuriano em relação às ideias do mestre francês, tratando a questão das possibilidades de uma abordagem histórica do sentido. Allana Cristina Moreira Marques apresenta uma leitura da noção de relação na reflexão teórica do neogramático Hermann Paul em cotejo com a elaboração teórica de Saussure em Restabelecendo as relações fundamentais: da linguística bistórica à linguística moderna. Em Saussure: a alguns passos da enunciação, Débora Facin e Claudia Toldo discutem os conceitos de língua, linguagem e signo partindo de uma concepção semiológica envolvendo o encontro de Ferdinand de Saussure e Émile Benveniste

Encerrando os artigos inéditos deste número temos: Dos limites da redução do pensamento saussuriano ao movimento estruturalista de Daiane Neumann e Aroldo Garcia dos Anjos, que discute a associação de Ferdinand de Saussure, em especial do Curso, ao movimento estruturalista; A linguística saussuriana no Brasil no início do século XXI de Clemilton Lopes Pinheiro, que apresenta um breve panorama sobre a linguística saussuriana no Brasil neste século e Pensando a tradução com Saussure: uma outra consideração da sincronia e da diacronia, no qual Sara Luiza Hoff avalia como os conceitos de sincronia e diacronia se relacionam à prática tradutória.

Três importantes artigos especialmente traduzidos do francês por Marcio Alexandre Cruz e Alexandre Sales Macedo Barbosa também compõem este número.

O espirito de Saussure: recepşão e herança (a herança linguística saussuriana: Paris contra Genebra) de Christian Puech enfrenta a ideia de uma "oposição” Paris/Genebra, presente já há muito tempo na historiografia/geografia da formação do pensamento de Saussure, que 
procura determinar o momento preciso e o lugar geométrico exato da precipitação das ideias contidas no Curso. Em seu lugar, o autor propõe uma análise da relação Paris/Genebra partindo do "destino" do texto saussuriano, levando em conta não só a gênese de seu pensamento, mas igualmente sua "produtividade" particularmente fecunda. A partir desse ponto de vista a problemática da localização geográfica do "verdadeiro" Saussure encontra seu limite e obriga antes a precisar que tipo de determinação temporal implica com ela a noção de "herança".

O Curso em busca de autor de Jürgen Trabant avalia as consequências da substituição de O Curso de Linguística Geral, edições de 1916/1922, um dos livros mais importantes da história da linguística, pelo Curso de Linguística Geral de Ferdinand de Saussure, edições 1967/1972, com os comentários de Tullio de Mauro, que dão ao Curso uma profundidade filológica (biografia, documentos, tradições) que o transformam radicalmente.

A sombra do Curso (1960-1980), de Pierre-Yves Testenoire, parte da afirmação de que o depósito dos manuscritos de Ferdinand de Saussure junto à Biblioteca Pública e Universitária de Genebra por seus descendentes possibilita uma série de importantes trabalhos de filólogos saussurianos e suscita uma reconfiguração interna do corpus saussuriano. Embora imediatamente lidos e assimilados pelos especialistas, esses trabalhos tardarão a abalar significativamente a percepção comum da linguística saussuriana feita unicamente a partir do CLG. Por outro lado, os anagramas, que não têm diretamente muita coisa a ver com seu ensino de linguística geral, modificarão de maneira mais imediata e mais visível a leitura do CLG. Em seu texto, Testenoire estuda esse momento específico da recepção saussuriana, quando a leitura do Curso de Linguística Geral encontra a dos anagramas.

Saussure e Benveniste no Brasil: quatro aulas na École Normale Supérieure, de Valdir do Nascimento Flores, que oferece um panorama da história crítica e pessoal da recepção das ideias de Ferdinand de Saussure e de Émile Benveniste no Brasil, é resenhado por Francisco Jeimes de Oliveira Paiva.

Para concluir nosso volume, reproduzimos a entrevista concedida a Rosa Attié Figueira pelo presidente do Cercle Ferdinand de Saussure e presidente do conselho editorial dos Cabiers Ferdinand de Saussure, Daniele Gambarara, por ocasião de sua participação, em 2016, de evento comemorativo do centenário do "Curso de Linguística Geral” no IEL/Unicamp. 
Esperamos, mais que registrar a relevância da reflexão em torno da fortuna teórica do mestre suíço Ferdinand de Saussure, estimular outros estudos e abordagens que se proponham a enfrentar as questões histórico-epistemológicas que passam necessariamente pelo autor, assim como pela linguística de seu tempo e a que a ele se seguiu. A fragmentação dos saberes, sua forte especialização na atualidade, restringiu a produção de uma reflexão crítica de caráter mais geral em torno da prática quotidiana de apreensão da linguagem feita pelo linguista. Buscamos com esse número temático da revista Leitura contribuir igualmente com essa tarefa que nos parece urgente e intelectualmente muito estimulante.

Além disso, parece-nos oportuno registrar o fato de que muitos dos nossos colaboradores são jovens pesquisadores brasileiros em formação ou recém-formados, que dão testemunho de que há de fato uma nova geração de saussurianos, sem dúvida renovada pelas recentes descobertas de manuscritos do autor, mas sobretudo pelos efeitos dessa nova recepção das ideias do mestre genebrino em tempos de comemoração de centenários. A reunião de pesquisadores em diferentes instituições de pesquisa e ensino pelo mundo e as muitas publicações recentes motivadas pelos centenários da morte de Saussure e da publicação do Curso fizeram, sem dúvida, "girar as mesas", brincando um pouco com a expressão de Puech, para nos referirmos ao contexto brasileiro desse novo retorno do "espírito de Saussure".

Marcio Alexandre Cruz

Núbia Rabelo Bakker Faria

(Organizadores)

\section{Referências}

AUROUX, Sylvain. Les antinomies méthodologiques. In: Histoire des idées

linguistiques T. 3 L'hégémonie du comparatisme. Liège: Pierre Mardaga, 2000, p. 409440 .

BISCONTI, Valentina; CHIDICHIMO, Alessandro. [Compte rendu de:] Saussure / John E. Joseph. Oxford: Oxford University Press, 2012. Histoire Epistémologie Langage, v. $38, n^{\circ} 1$, p. 159-166, 2016. 
BRONCKART, Jean-Paul; BOTA, Cristian. Dynamique et socialité des faits linguistiques. In: BRONCKART, Jean-Paul; BULEA, Ecaterina; BOTA, Cristian (Org.) Le projet de Ferdinand de Saussure. Genebra; Paris: Librairies Droz, 2010, p. 193-213.

BRONCKART, Jean-Paul. Théories du langage. Bruxelas: Mardaga, 1977.

BOUQUET, S. Ontologie et épistémologie de la linguistique dans les textes originaux de Ferdinand de Saussure. Communication au Colloque international ICHoLS, Potsdam, 2008. Disponible sur: <http://www.revuetexto.net/index.php?id=1850>. Acesso em: 31 out. 2018.

BOUQUET, Simon. Saussure après un siècle. In: BOUQUET, Simon (Org.). Cahier de l'Herne: Ferdinand de Saussure. Paris: Éditions de L'herne, 2003, p. 11-15.

CALVET, Louis-Jean. Postface. In: SAUSSURE, Ferdinand de. Cours de linguistique générale [1916], publié par C. Bally et A. Sechehaye avec la collaboration de A. Riedlinger, édition critique préparée par Tullio de Mauro. Paris: Editions Payot \& Rivages, 1972, p. 505-513.

CHISS, Jean-Louis; PUECH, Christian, Fondations de la linguistique. Etudes d'histoire et d'épistémologie. Louvain-la-Neuve: Duculot, 1997.

Le langage et ses disciplines $\mathbf{X I X}^{\mathrm{e}}$ - $\mathbf{X X}^{\mathrm{e}}$ siècles. Paris; Bruxelles, De Boeck \& Larcier, Département Duculot, 1999.

CRUZ, Marcio Alexandre; PIOVEZANI, Carlos; TESTESNOIRE, Pierre-Yves. Saussure, o texto e o discurso. São Paulo: Parábola Editorial, 2016.

CRUZ, Marcio Alexandre. Por que (não) ler o Curso de linguística geral depois de um século? In: FARACO, C. A. (Org.). O efeito Saussure: cem anos do Curso de linguística geral. São Paulo: Parábola, 2016.

FARIA, Núbia R. B.; CASTRO, Maria Fausta P. de. Estudos saussurianos hoje. DELTA, São Paulo, v. 34, nº 3, jul./set. 2018.

NORMAND, Claudine. Saussure. 2 ed. Paris: Les Belles Lettres, 2004.

TESTENOIRE, Pierre-Yves. O que as teorias do discurso devem a Saussure. In: CRUZ, M. A.; PIOVEZANI, C.; TESTESNOIRE, P.-Y. Saussure, o texto e o discurso. São Paulo: Parábola Editorial, 2016, p. 105-124.

TRABANT, Jürgen. Faut-il défendre Saussure contre ses amateurs? Notes item sur l'étymologie saussurienne. Langages, v. 159, p. 111-124, 2005. 